\title{
How does progress towards the MDG 4 affect inequalities between different subpopulations? Evidence from Nepal
}

\author{
Kim-Huong Nguyen, ${ }^{1}$ Eliana Jimenez-Soto, ${ }^{1}$ Alison Morgan, ${ }^{2}$ Chris Morgan, ${ }^{3}$ \\ Andrew Hodge ${ }^{1}$
}

- Additional material is published online only. To view please visit the journal online (http://dx.doi.org/10.1136/jech2012-201503)

${ }^{1}$ School of Population Health, The University of Queensland, Brisbane, Queensland, Australia

${ }^{2}$ Nossal Institute for Global Health, The University of Melbourne, Melbourne, Victoria, Australia

${ }^{3}$ Centre for International Health, Burnet Institute, Melbourne, Australia

Correspondence to Dr Kim-Huong Nguyen, MDG 4\&5, School of Population Health, The University of Queensland, Public Health Building, Herston Road, Herston, Brisbane, QLD 4006, Australia;

kim.h.nguyen@uq.edu.au.

Received 9 May 2012 Revised 14 November 2012 Accepted 26 November 2012 Published Online First 15 January 2013

\footnotetext{
To cite: Nguyen $\mathrm{K}-\mathrm{H}$, Jimenez-Soto $E$, Morgan A et al. J Epidemiol Community Health 2013;67:311-319.
}

\section{ABSTRACT}

Background Few previous studies have examined nonwealth-based inequalities in child mortality within developing countries. This study estimates changes in under-5-year-olds and neonatal mortality in Nepal across a range of subnational levels, which allows us to assess the degree of equity in Nepal's progress towards Millennium Development Goal 4.

Methods Direct estimates of under-5-year-olds and neonatal death rates were generated for 1990-2005 using three Demographic and Health Surveys and two Living Standards Surveys by the following levels: national, rural/urban location, ecological region, development region, ethnicity and wealth. Absolute and relative inequalities were measured by rate differences and rate ratios, respectively. Additionally, wealth-related inequality was calculated using slope and relative indexes of inequality and concentration indices.

Results Estimates suggest that while most rates of under-5-year-olds and neonatal mortality have declined across the different equity markers, leading to a downward trend in absolute inequalities, relative inequalities appear to have remained stable over time. The decline in absolute inequalities is strongest for under-5-year-olds' mortality, with no statistically significant trend in either relative or absolute inequalities found for neonatal mortality. A possible increase in inequalities, at least in relative terms, was found across development regions, where death rates remain high in the mid-western region.

Conclusions By 2015, our estimates suggest that more than $65 \%$ of deaths of under-5-year-olds will occur in the neonatal period, with stable trends in neonatal mortality inequalities. These findings along with the fact that health outcomes for neonates are more highly dependent on health systems, suggest further equitable reductions in under-5-year-olds mortality will require broad health-system strengthening, with a focus on the improvement of healthcare services provided for mothers and newborns. Other inequities suggest continued special attention for vulnerable subpopulations is warranted, particularly to overcome social exclusion and financial barriers to care in urban areas.

\section{INTRODUCTION}

Nepal has been consistently praised by the international community for its achievements in improving maternal and child health outcomes. Despite 10 years of civil conflict, the country is almost certain to reach Millennium Development Goal (MDG) 4, and many studies have suggested that it is on track to meet the MDG $5 .{ }^{1-3}$ Consequently,
Nepal received the Achievement Award for its progress in reducing maternal mortality at the United Nations 2010 MDG Summit. Recent reforms demonstrate Nepal's commitment to improve maternal and child health. Key features since the ceasefire in 2006 include: the introduction of free essential health services and drugs for the entire population; free healthcare for the very poor; an incentive programme for mothers to deliver at facilities; and free maternity care at all government facilities. ${ }^{3} 4$

Questions remain, however, regarding the extent to which Nepal's progress has been equitable. Previous studies have shown that rough topography, combined with vast differences in economic development, infrastructure and service availability, contribute heavily to economic and social exclusion, and have important implications for the delivery of health services and outcomes. ${ }^{5-8}$ Regional disparities in poverty are immense, mainly due to unbalanced development in the past. ${ }^{9}$ Most doctors and health facilities are concentrated in urban areas and in the relatively developed central and western development regions, as opposed to the mid- and far western regions, which were the most affected during the conflict. ${ }^{6}{ }^{10}$ The use of skilled birth attendants is higher in the hills and plains than in the mountains, and higher in the central than in the mid- and far western regions. ${ }^{111} 12$ Urban children also appear to have a better chance of survival than rural children, ${ }^{13}$ while urban mothers have better access to antenatal care and are more likely to deliver in a health facility. ${ }^{14}$

Social and ethnic inequalities may also relate to restricted access to basic economic opportunities and services for lower-caste groups. The Dalits, Muslims, and Terai Madhesis have long faced marginalisation, as shown by the concentration of poverty and poor health, education and empowerment outcomes. ${ }^{15-18}$ The gap in economic wealth between different ethnic groups is also large and persistent. ${ }^{16} 19$ Previous studies suggest that the Newars, the Hill and Madhesi Brahmans are doing well economically, while the Dalits are clustered in the bottom wealth group. ${ }^{15}$

In this paper, we focus on absolute and relative inequalities in child health. We examined levels and distributions of under-5-year-olds and neonatal death rates (NDR), and trends in measures of inequality across a range of equity markers. Very little evidence exists on whether substantial progress of health outcomes at a national level masks substantial inequalities across subpopulations. Studies, to date, have primarily emphasised wealth-based 
inequality. ${ }^{20-23}$ However, such focus may lead to an incomplete picture of the degree and source of inequalities. In Nepal, there are many inter-related factors which potentially influence service utilisation rates and health outcomes, including economic, location, cultural, religious and social beliefs and norms (eg, entrenched ethnicity-based hierarchies). ${ }^{16}$ We therefore expand the measurement of inequality to various markers that have been acknowledged as important divisions of the Nepalese society and, more generally, in developing countries. To our knowledge, no previous study has provided a comprehensive nationally representative analysis of equitable progress in health outcomes. Such an examination is important for two reasons. First, persistent within-country inequity reduces the effectiveness of national objectives of improving livelihoods. Second, disaggregated monitoring will help strengthen evidence-based management and improve targeting of health services to counter exclusion.

\section{METHODS}

\section{Data}

The analyses are based on data from two survey series: the Nepal Demographic and Health Surveys (NDHS 1996, 2001 and 2006), and the Nepal Living Standards Surveys (NLSS I 1995-96 and II 2003-04). Both series utilised a two-stage stratified sampling scheme and provided nationally representative population descriptions. Full details are available elsewhere, and notably, civil conflict did not pose any important disruption to sampling. ${ }^{1} 12 \quad 24-26$ The NLSS I and NLSS II sampled 3373 (4789) and 5072 (5375) households (women aged 15-49 years) from 274 and 421 primary sampling units (PSU), respectively. The PSUs were subward, ward or a group of wards in the rural areas, and subward or ward in the urban areas. A total number of 235, 257 and 260 PSUs were sampled in the 1996, 2001 and 2006 waves of the NDHS, respectively. The corresponding households (women aged 15-49 years) samples were 8082 (8429); 8602 (8726); and 8707 (10 793), respectively.

Both the NLSS and the NDHS collect data relating to demographic and socioeconomic indicators. As the input for the mortality estimation, both series included complete birth history $(\mathrm{CBH})$ modules, in which female respondents are asked about every child they have ever borne. In the absence of a vital registration system, complete birth histories are the preferred method to monitor trends in child mortality. ${ }^{27}$ The combined dataset contained 107446 children ever borne, under the age of five years.

\section{Mortality estimates}

Following the methods of Rajaratnam et $a l,{ }^{27}$ death rates were estimated directly using $\mathrm{CBH}$. Mortality among children aged 5 years and younger was estimated biennially due to the relative rarity of deaths in that age group in Nepal. The estimation procedure is identical at both national and subnational levels.

The 2-year estimates were created by pooling all the data from all the surveys. The child death rate was then estimated by detailing the life or death in each month of the first 5 years of each child's life, denoted person-months. Six age groups (0-1 month, 1-11 months, 12-23 months, 24-35 months, 36-47 months and 48-59 months) were created for the calculation of survival rates. For each age group, the mean survival probability was estimated by dividing the total number of person-months where children were alive by the total number of person-months, accounting for sample weights. Under-5-year-olds (U5DR) and NDR were then derived by subtracting the amalgamation of the survival rates of the associated age groups from 1 .
Confidence intervals were constructed following the procedure employed by Rajaratnam et al. ${ }^{27}$ For each time-period/ age-group, 1000 simulations of the survival probability were generated by assuming a binomial distribution where the probability equals the mean survival probability, and sample size is the number of person-months observed in the time-period/agecategory. The death rate was then calculated for each timeperiod in each simulation. The lower and upper confidence bounds on the estimates for each time-period were extracted from the percentiles 2.5 and 97.5. To produce a continuous series, Loess regression was applied, using a smoothing parameter of $0.5 .^{28}$ The prediction toward 2015 uses the last set of parameter estimates for the Loess regression and standard methods to capture uncertainty in the forecast. ${ }^{29}$

\section{Equity markers and measures of inequalities}

We selected five equity markers for which data were available, and that best represented the diversity of the country. We investigated inequalities by rural/urban location; by ecological region: mountain, hill or terai (ie, plains); and by development region: central, eastern, western, mid-western, or far western. In addition, following the categorisation in the literature, ${ }^{7} 1516$ we grouped all castes/ethnic groups into six broad categories: Brahmans/Chhetris, Terai Madhesis, Dalits, Newars, Janajatis, Muslims and others (ie, Marwaris, Bengalis, Jains, Punjabis/ Sikhs and unidentified others).

The fifth equity marker examined was wealth. Given that income and expenditure data are absent in both survey series, we constructed a wealth index, using principal components analysis. ${ }^{30}$ The assets used for the wealth index include housing materials, ownership of durable goods and access to improved water and sanitation facilities. We constructed separate wealth indices for each survey and tested the extent to which the classifications of households according to their wealth indices were influenced by the choice of assets and the choice of sample. The test results (not reported) suggest that the individual-survey wealth indices were robust; the ranking and classification of households did not change greatly from one index to the next, and the indices are highly correlated. Thus, for each survey, we created a wealth index using all the households in the sample, of which the average range is between -2.5 and 13.5. The wealth index is then used to rank households from poorest to richest, and to divide the sample into five wealth quintiles.

Given the importance of both absolute and relative measures of inequalities, we computed rate difference (RD) and the slope index of inequality (SII) as well as rate ratio (RR) and the relative index of inequality (RII). ${ }^{31-33}$ The advantages of the RIIs and SIIs over the RDs and RRs are well known. ${ }^{33}$ The RII and SII are computed via weighted linear regression of the death rates on the midpoint of the cumulative population distribution ranked by a socioeconomic indicator. ${ }^{34}$ Unfortunately, the need for ordinal social groups to rank the population implies that the RIIs and SIIs can only feasibly be computed using the wealth equity marker. For the non-wealth equity markers, RDs and RRs are computed for each subpopulation in reference to a base group. In each case, the group with the lowest average under-5-year-olds' death rate over the sample period is chosen as the referent. confidence intervals for the RIIs and SIIs were calculated using standard methods discussed by Hayes and Berry $^{35}$; and for the RDs and RRs, were computed using the simulation process utilised for the mortality estimates described in the previous subsection.

We also utilised the concentration index (CI) to further assess the degree of relative wealth-related inequalities using 
microdata. ${ }^{36}$ The higher the absolute value of a CI, the higher the inequality between the rich and the poor and a negative CI indicates that children from households with higher socioeconomic status have better health outcomes (ie, less mortality) than children from the least-advantaged households. Given that the outcome variable is binary, the CI is bounded by the prevalence of mortality. ${ }^{37}$

Finally, to gauge changes in disparities over time we compared the death rates and measures of inequalities - and corresponding 95\% confidence intervals-over the sample period and computed tests of the statistical significance of a linear trend in these estimates. ${ }^{33}$ In the cases of RRs and RIIs, we used the natural logarithm of these measures in the regressions. In the tables, for RDs, SIIs and CI, we report the trend coefficient and corresponding $\mathrm{p}$ values. These statistics can be interpreted as the average absolute change per period in the inequality measures over the sample. In the cases of RRs and RIIs, we report the exponentiated trend coefficients, and these statistics can be interpreted as the average ratio change in RR or RII per period.

All statistical analyses were conducted using the two software programs, Stata and R.

\section{RESULTS}

Our analysis confirms Nepal's progress towards achieving MDG 4. Figure 1 presents national estimates of the U5DR and NDR, and for rural and urban location. The full set of 2-year results for all equity makers is presented in the online appendix. Figure 1 demonstrates that death rates have continuously fallen since 1990. The U5DR has fallen from 121 (95\% CI 113 to 129) deaths per 1000 live births in 1990-1991 to 61 (95\% CI 47 to 74 ) in 2004-2005. This implies an average annual rate of reduction of approximately $5.2 \%$. If this trend continues, U5DR is predicted to drop to approximately 31 (95\% CI 21 to 45) by 2015, which is well below the set target. The rates of reduction in the NDR were lower, with an average of $3.7 \%$ reduction per year. Were this reduction rate to continue, NDR would decline to approximately 20 (95\% CI 10 to 31 ) by 2015 . Accordingly, by that year, more than $65 \%$ of under-5-year-olds' deaths will be among neonates.

The death rates for urban children are generally lower than their rural counterparts; however, the difference between the two groups appears to have reduced markedly. By 2004-2005, the urban U5DR was estimated to be 50 (95\% CI 20 to 88 ) compared with the rural U5DR of 64 (95\% CI 45 to 73 ). Projections suggest that the urban-rural gap will be negligible by 2015. For both U5DRs and NDRs, the diminishing absolute disparity between two populations appears to be due to faster progress in rural areas, and stagnation within the urban population since the late 1990s.

To confirm these observations and to assess relative changes, table 1 presents measures of absolute (ie, RD) and relative (ie, RR) inequalities across the non-wealth equity markers. For U5DR, across most groups within each of the non-wealth equity markers, a consistent pattern of narrowing absolute inequalities, and no clear evidence of a change in relative inequalities over time is observed. For instance, when comparing U5DR with urban and rural populations, the RDs dropped from 40.4 (95\% CI 19.3 to 59.3 ) in $1990-1991$ to 13.8 (95\% CI -20.4 to 42.8 ) in 2004-2005, while the RRs changed little from 1.48 (95\% CI 1.19 to 1.88 ) to 1.27 (95\% CI 0.74 to 2.52 ) over the same period. Only the RDs show a significant downward trajectory at conventional levels. While this pattern is generally observed with respect to NDRs, the trends in either relative or absolute inequalities are not significant at conventional levels, which is expected given the lower reduction in neonatal rates over the sample period. The only exception is the statistically significant reduction in neonatal RDs in the rural Terai.

Reductions in RDs are evident for ecological regions, particularly when regional estimates are disaggregated by urban/rural residence. Figure 2 shows that the absolute difference in U5DRs has narrowed, yet the mortality profile for the urban Terai was unique. In this region, the U5DR has increased in the three periods since a low of 57.8 (95\% CI 36.8 to 81) in 1998-1999. Consequently, it is the only ecological region that has not experienced a statistically significant reduction in RDs over the sample period. By contrast, the other rural ecological regions have shown consistent declines in U5DR, while some increases in U5DR have been observed in the urban Hill region in 20022003 and 2004-2005. In addition, a spike in the NDR is observed in the urban Terai in 2002-2003.

A noteworthy exception to the general pattern is the increase in relative and absolute inequalities for some development regions. Positive trends in RRs for under-5-year-olds and neonatal mortality are observed in a majority of the regions, and corresponding RDs have increased the mid-western and western regions, consistent with increasing inequality. However, one should note that only the trend in RRs for U5DRs in the mid-western region is significant at conventional levels. Accordingly, as displayed in figure 3, relatively high levels of under-5-year-olds' and neonatal mortality are experienced in the mid-western region, particularly since 2000-2001. In addition, the western region has experienced some increases in neonatal mortality since the same period, which is confirmed by the close to statistically significant positive trend in neonatal RDs in this region. There is some evidence to suggest that relative inequalities in ethnic neonatal morality have increased; however, these results are somewhat unstable due to statistical imprecision.

The full gambit of wealth-related inequality measures are presented in table 2 . The estimates again suggest that absolute inequalities in under-5-year-olds' mortality have possibly decreased, while relative inequalities have stabilised. A similar pattern is observed for neonatal mortality; however, none of the trends are significant at conventional levels.

\section{DISCUSSION}

Our findings show that, regardless of continued substantial reductions in national U5DRs and NDRs, inequalities across Nepal's subpopulations remain, at least in relative terms. Consequently, a country's successes at a national level, while important, should, nevertheless, be assessed in combination with subnational performance.

We found that national U5DRs and NDRs were declining since 1990 , at a mean rate of decline of $5.2 \%$ and $3.7 \%$ per year, respectively, which exceeds the required rate to meet the MDG 4 target. Our estimates are lower than some previous reports $^{38}$ but are consistent with others that use comparable methods. ${ }^{27} 39$ The slower reduction in the NDR compared with the U5DR is to be expected. In general, preventive public health measures, such as immunisation and community management of diarrhoea and acute respiratory infections, are likely to have greater efficacy against the usual causes of death in older children compared with newborns. Ghimire et al ${ }^{40}$ have described the national scale-up of community-based case management of diarrhoea and acute respiratory infections, and of prevention strategies in Nepal over our study period. Further reductions in U5DR would require broad health-system strengthening for integrated improvement in care during pregnancy, childbirth and the neonatal period. This is arguably a more challenging 
Figure 1 Under-5-year-old and NDR (per 1000 live births) at the national level and by rural and urban location: actual 1990-2005; projected to 2015. National estimates by source and using the pooled data are displayed. The solid and semibroken lines represent the continuous mortality estimates calculated from the 2-year estimates, while the shaded area signifies the corresponding $95 \%$ confidence intervals.Cl, confidence intervals; DHS, Demographic Health Survey; NLSS, Nepal Living Standards Surveys; NDR, neonatal death rate; U5DR, under-5-year-olds' death rate. This figure is only reproduced in colour in the online version.

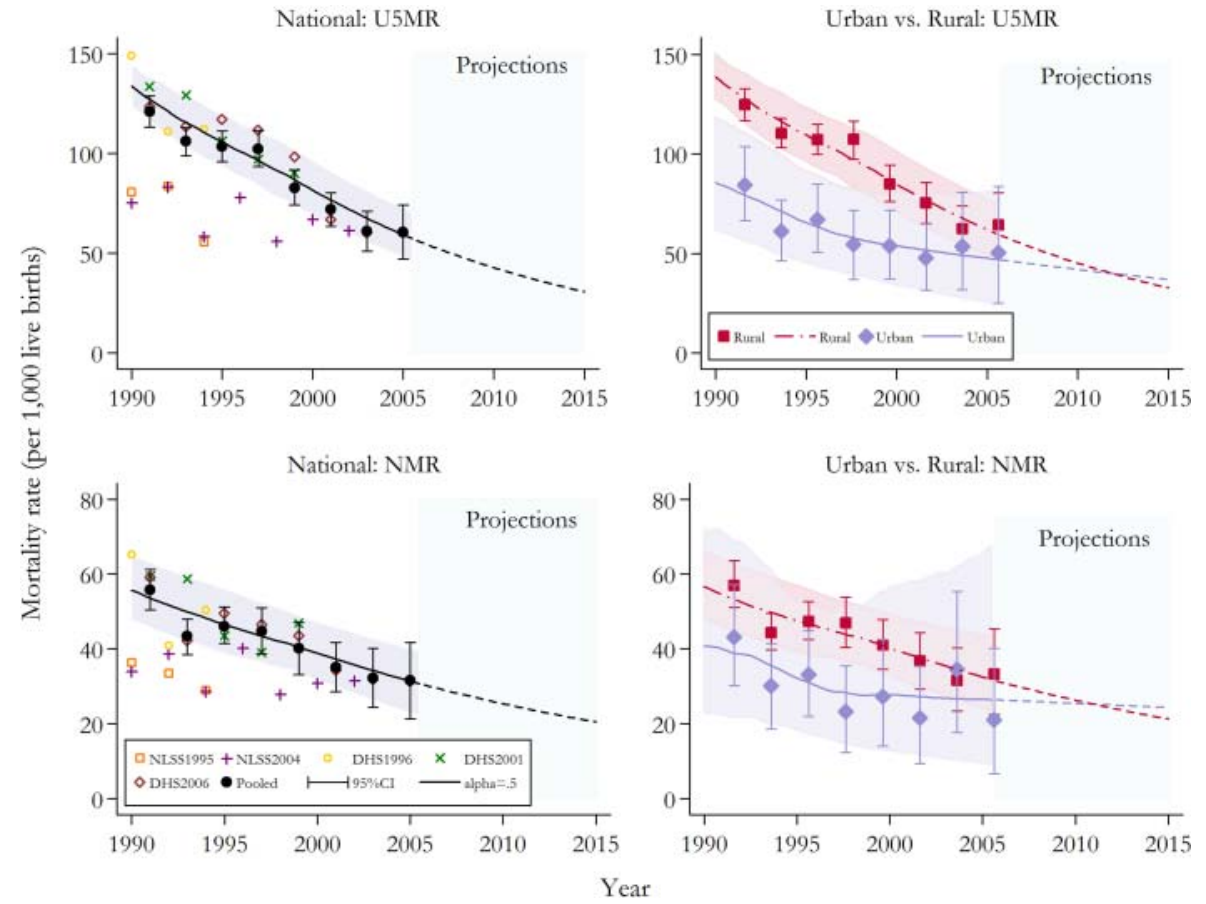

task, given that coverage remains relatively low in key interventions relevant to neonatal health, such as facility-based childbirth, skilled attendance at birth and postnatal care. ${ }^{1} 1112$

The description of variable progress according to ecological and development regions - with least progress in the mountains and in the mid-western and western regions, respectively_suggest that progress is not evenly shared. The mountain ecological region is home to just $7 \%$ of the population, and providing clinical services to remote areas is difficult due to both the costs involved and the challenge of retaining staff. Until 2009, there were no comprehensive obstetrics services in any of the mountain districts. Consequently, there remain enormous challenges to provide for mountain communities. Of related interest is the increased trend in inequalities across development regions (which each include mountain, hill and terai ecologies); most especially in relative terms. Potential explanations for this-not testable by this analysis -may lie in these settings' greater poverty, poorer access to health services, the civil conflict that was greatest in the far and midwestern regions, and outward migration.

Even in cases where absolute inequalities appear to be declining, such as between rural and urban populations, a number of concerning trends persist. First, while U5DRs and NDRs have rapidly declined in rural areas from a high mortality baseline, this most likely represents the result of easily achievable gains obtained through the scale-up of community- and populationbased services, such as preventive care, including immunisation, which the urban population had already achieved. ${ }^{40}$ The minimal gains in the NDR of the urban population since the late 1990s, together with the possible narrowing of the absolute rural/urban disparity in NDR, suggest that the rural population might be approaching the end of this opportune period.

Second, the stagnation of urban death rate reductions, both at an aggregate level and within the terai and hill regions, coincides with a number of reports, ${ }^{41}$ which have noted the increasing problems in urban slums. Poor housing and urban planning, ${ }^{42}$ weak transportation systems, limited access to care ${ }^{43}$ and overcrowding can all worsen health outcomes, ${ }^{44} 45$ which can be exacerbated by political instability in rural areas that, in turn, lead to a rapid influx of migrants into urban areas. ${ }^{46}$ The growth in the urban population has not been matched by increased health services, and the government, up until 2010, had no programmes to deliver routine or acute care services to slum dwellers. ${ }^{47}$

While inequalities in under-5-year-olds' mortality have declined, disparities in neonatal mortality between ethnic groups appear to be persistent, with all ethnic groups showing signs of a possible increase in relative inequalities compared with the Newars. The Dalits and Terai Madhesi groupings continue to experience higher relative levels of neonatal mortality. While this finding has been previously observed, ${ }^{7} 1516$ our analyses suggest that past programmes targeting ethnicity-based inequality have not been effective. Other studies have shown that these groups consistently have the lowest coverage across most maternal and child health interventions. ${ }^{111} 12$ One should note, however, that due to the constant evolution in the definition of each caste group over the study period, caution is required when interpreting trends over time.

NDHS 2006 data suggest that more than 98\% of Terai Madhesis, and approximately $50 \%$ of Dalits live in the terai. ${ }^{12}$ This corresponds with our other findings regarding disadvantage in the terai; where, given the flatter topography and better roads, infrastructure and service provision should be physically easier than in the hill and mountain regions. The population increase in the terai without parallel increase in health facilities may, in part, explain the persistent disadvantage. It is clearly not sufficient to simply live close to services; it is likely that cultural or social factors other than location determine the utilisation of health interventions and, consequently, the mortality outcomes (especially neonatal) of the Dalits and Terai Madhesis.

A notable strength of our analysis is the availability of highquality, relatively large population-based datasets. Nonetheless, three important limitations remain. First, due to the relatively small sample size for each group, large confidence intervals are associated with some wealth and ethnic death rates, especially for the last biennial period. Accordingly, caution should be exercised when asserting the degree of inequality. However, the 
Table 1 Inequalities in under-5-year-olds and neonatal mortality (per 1000 live births) by non-wealth equity markers for selected years, with $95 \%$ confidence intervals and $p$ values for trend

\begin{tabular}{|c|c|c|c|c|c|c|c|c|}
\hline \multirow[b]{2}{*}{ Equity marker } & \multicolumn{4}{|l|}{ U5DR } & \multicolumn{4}{|l|}{ NDR } \\
\hline & RR & $95 \% \mathrm{Cl}$ & RD & $95 \% \mathrm{Cl}$ & RR & $95 \% \mathrm{Cl}$ & RD & $95 \% \mathrm{Cl}$ \\
\hline \multicolumn{9}{|c|}{ Urban/rural (base=urban) } \\
\hline \multicolumn{9}{|l|}{ Rural } \\
\hline 1990-1991 & 1.48 & (1.19 to 1.88 ) & 40.4 & (19.3 to 59.3$)$ & 1.32 & (0.96 to 1.92 ) & 13.8 & $(-2.4$ to 28.7$)$ \\
\hline 1998-1999 & 1.58 & (1.15 to 2.36$)$ & 31.3 & (10.8 to 51.4$)$ & 1.50 & (0.95 to 3.14 ) & 13.8 & (-2.0 to 28.7$)$ \\
\hline 2004-2005 & 1.27 & (0.74 to 2.52 ) & 13.8 & ( -20.4 to 42.8$)$ & 1.59 & (0.70 to 6.49$)$ & 12.3 & $(-12.2$ to 33.9$)$ \\
\hline Trend ( $p$ value) & 0.959 & $(0.119)$ & -5.326 & $(0.011)$ & 0.990 & $(0.801)$ & -1.224 & $(0.316)$ \\
\hline \multicolumn{9}{|c|}{ Ecological region (base=hill) } \\
\hline \multicolumn{9}{|c|}{ Mountain } \\
\hline 1990-1991 & 1.80 & (1.48 to 2.16$)$ & 82.7 & (51.9 to 114.1 ) & 1.44 & (1.05 to 1.87$)$ & 20.6 & (2.7 to 38.5 ) \\
\hline 1998-1999 & 1.69 & (1.23 to 2.28$)$ & 48.3 & (18.6 to 79.8 ) & 1.20 & (0.68 to 2.09 ) & 7.2 & $(-13.6$ to 28.9$)$ \\
\hline 2004-2005 & 1.99 & (1.03 to 3.66$)$ & 50.5 & (1.5 to 102.0$)$ & 1.47 & (0.43 to 3.61$)$ & 13.8 & $(-19.9$ to 53.0$)$ \\
\hline Trend ( $p$ value) & 1.020 & $(0.050)$ & -4.424 & $(0.011)$ & 0.993 & $(0.835)$ & -1.185 & $(0.489)$ \\
\hline \multicolumn{9}{|l|}{ Terai } \\
\hline 1990-1991 & 1.22 & (1.06 to 1.4 ) & 22.8 & (7.0 to 37.5 ) & 1.30 & (1.06 to 1.61$)$ & 14.2 & (3.3 to 25.1 ) \\
\hline 1998-1999 & 1.27 & (0.99 to 1.65$)$ & 18.9 & $(-0.7$ to 37.5$)$ & 1.27 & (0.86 to 2.03 ) & 9.7 & $(-6.9$ to 25.5$)$ \\
\hline 2004-2005 & 1.34 & (0.82 to 2.2 ) & 17.5 & $(-10.7$ to 45$)$ & 1.15 & (0.58 to 2.36$)$ & 4.4 & $(-17.1$ to 26.3$)$ \\
\hline Trend ( $p$ value) & 1.020 & $(0.097)$ & -0.106 & $(0.920)$ & 0.984 & $(0.465)$ & -1.179 & $(0.21)$ \\
\hline \multicolumn{9}{|c|}{ Ecological region stratified by rurality (base=hill: urban) } \\
\hline \multicolumn{9}{|c|}{ Mountain: rural } \\
\hline 1990-1991 & 2.81 & (1.97 to 4.37$)$ & 123.4 & (85.6 to 160.8 ) & 2.00 & (1.18 to 4.25$)$ & 35.4 & $(10.2$ to 61.0$)$ \\
\hline 1998-1999 & 2.27 & (1.33 to 4.69$)$ & 65.7 & (25.0 to 103.9 ) & 1.23 & (0.59 to 3.7$)$ & 8.3 & $(-23.1$ to 36.0$)$ \\
\hline 2004-2005 & 1.50 & (0.67 to 3.88 ) & 32.8 & (-33.7 to 95.0$)$ & 1.46 & (0.41 to 8.78 ) & 12.9 & ( -29.4 to 56.5$)$ \\
\hline Trend ( $p$ value) & 0.930 & $(0.093)$ & -12.612 & $(0.002)$ & 0.952 & $(0.507)$ & -3.603 & $(0.231)$ \\
\hline \multicolumn{9}{|l|}{ Hill: rural } \\
\hline 1990-1991 & 1.58 & (1.14 to 2.43 ) & 39.6 & (12.1 to 66.0$)$ & 1.37 & (0.83 to 2.89 ) & 12.9 & (-9.9 to 32.9$)$ \\
\hline 1998-1999 & 2.31 & (0.61 to 5.8 ) & 67.6 & $(-24.3$ to 190.7$)$ & 2.34 & (0.01 to 9.59 ) & 47.6 & $(-48.2$ to 169.0$)$ \\
\hline 2004-2005 & 0.84 & (0.39 to 2.11 ) & -10.7 & $(-67.3$ to 34.1$)$ & 1.04 & (0.35 to 6.35 ) & 1.2 & $(-35.9$ to 32.6$)$ \\
\hline Trend ( $p$ value) & 0.927 & $(0.162)$ & -6.546 & $(0.089)$ & 0.986 & $(0.771)$ & -0.780 & $(0.738)$ \\
\hline \multicolumn{9}{|l|}{ Terai: rural } \\
\hline 1990-1991 & 1.90 & (1.37 to 2.91 ) & 61.2 & (33.4 to 88.4 ) & 1.77 & (1.09 to 3.83 ) & 27.1 & (4.7 to 49.3 ) \\
\hline 1998-1999 & 2.12 & (1.22 to 4.34$)$ & 57.8 & (18.4 to 96.7) & 1.85 & (0.83 to 5.7 ) & 30.3 & $(-9.8$ to 68.1$)$ \\
\hline 2004-2005 & 1.05 & (0.51 to 2.55 ) & 3.5 & $(-58.2$ to 49.4$)$ & 1.27 & (0.48 to 7.02 ) & 7.5 & $(-28.4$ to 36.9$)$ \\
\hline Trend ( $p$ value) & 0.933 & $(0.091)$ & -7.466 & $(0.01)$ & 0.953 & $(0.244)$ & -2.716 & $(0.060)$ \\
\hline \multicolumn{9}{|l|}{ Terai: urban } \\
\hline 1990-1991 & 1.49 & (0.98 to 2.45 ) & 33.7 & $(-1.6$ to 70.0$)$ & 1.45 & (0.74 to 3.15$)$ & 15.7 & $(-12.8$ to 43.8$)$ \\
\hline 1998-1999 & 1.12 & (0.58 to 2.43 ) & 6.2 & (-31.4 to 42.8$)$ & 0.51 & (0.14 to 1.83 ) & -17.3 & $(-47.1$ to 10.7$)$ \\
\hline 2004-2005 & 1.35 & (0.48 to 3.72 ) & 22.9 & ( -55.9 to 92.2$)$ & 0.84 & (0.17 to 4.92 ) & -4.4 & ( -36.3 to 32.1$)$ \\
\hline Trend ( $p$ value) & 1.020 & $(0.654)$ & 0.843 & $(0.772)$ & 0.979 & $(0.820)$ & -0.594 & $(0.842)$ \\
\hline \multicolumn{9}{|c|}{ Development region (base=Eastern) } \\
\hline \multicolumn{9}{|c|}{ Mid-western } \\
\hline 1990-1991 & 1.50 & (1.24 to 1.86$)$ & 48.9 & (24.8 to 74.2 ) & 1.22 & (0.86 to 1.73 ) & 10.4 & $(-7.9$ to 28.4$)$ \\
\hline 1998-1999 & 1.40 & (1.01 to 1.93 ) & 27.3 & (0.5 to 54.1$)$ & 1.00 & (0.56 to 1.69$)$ & -0.01 & $(-19.5$ to 22.6$)$ \\
\hline 2004-2005 & 2.22 & (1.16 to 4.18$)$ & 64.5 & (10.8 to 116.8 ) & 2.23 & (0.88 to 5.77$)$ & 37.8 & $(-5.2$ to 83.7$)$ \\
\hline Trend ( $p$ value) & 1.056 & $(0.037)$ & 1.836 & $(0.432)$ & 1.073 & $(0.158)$ & 3.059 & $(0.197)$ \\
\hline \multicolumn{9}{|l|}{ Far western } \\
\hline 1990-1991 & 1.56 & (1.26 to 1.96$)$ & 54.0 & (27.7 to 82.7 ) & 1.51 & (1.05 to 2.20$)$ & 24.4 & (2.4 to 48.5$)$ \\
\hline 1998-1999 & 1.54 & (1.13 to 2.08$)$ & 36.8 & (9.9 to 64.2$)$ & 1.27 & (0.75 to 2.00 ) & 10.3 & $(-10.6$ to 31.4$)$ \\
\hline 2004-2005 & 1.31 & (0.70 to 2.47 ) & 16.1 & $(-21.1$ to 52.5$)$ & 0.42 & (0.06 to 1.25$)$ & -17.8 & $(-42.1$ to 3.9$)$ \\
\hline Trend ( $p$ value) & 1.016 & $(0.584)$ & -1.803 & $(0.546)$ & 0.914 & $(0.211)$ & -2.879 & $(0.277)$ \\
\hline \multicolumn{9}{|l|}{ Western } \\
\hline 1990-1991 & 1.09 & (0.86 to 1.33 ) & 8.8 & (-14.6 to 28.7$)$ & 0.99 & (0.71 to 1.39 ) & -0.3 & $(-15.6$ to 14.9$)$ \\
\hline 1998-1999 & 1.11 & (0.80 to 1.53 ) & 7.5 & $(-15.3$ to 31.1$)$ & 1.06 & (0.63 to 1.65 ) & 2.3 & (-16.0 to 21.3 ) \\
\hline 2004-2005 & 1.38 & (0.70 to 2.71 ) & 20.3 & (-20.5 to 61.3$)$ & 1.53 & (0.56 to 3.8 ) & 16.2 & $(-19.5$ to 51.7$)$ \\
\hline Trend ( $p$ value) & 1.024 & $(0.248)$ & 1.355 & $(0.343)$ & 1.056 & $(0.145)$ & 2.069 & $(0.108)$ \\
\hline
\end{tabular}


Table 1 Continued

\begin{tabular}{|c|c|c|c|c|c|c|c|c|}
\hline \multirow[b]{2}{*}{ Equity marker } & \multicolumn{4}{|l|}{ U5DR } & \multicolumn{4}{|l|}{ NDR } \\
\hline & RR & $95 \% \mathrm{Cl}$ & RD & $95 \% \mathrm{Cl}$ & RR & $95 \% \mathrm{Cl}$ & RD & $95 \% \mathrm{Cl}$ \\
\hline \multicolumn{9}{|l|}{ Central } \\
\hline 1990-1991 & 1.32 & (1.09 to 1.61$)$ & 31.0 & (9.6 to 51.7$)$ & 1.20 & (0.89 to 1.62 ) & 9.7 & (-6.4 to 23.6$)$ \\
\hline 1998-1999 & 1.33 & (0.97 to 1.81 ) & 22.4 & $(-2.3$ to 47.1$)$ & 1.12 & (0.67 to 1.86$)$ & 4.7 & (-14.7 to 26.3$)$ \\
\hline $2004-2005$ & 0.96 & (0.52 to 1.85$)$ & -2.2 & $(-33.3$ to 29.3$)$ & 0.69 & (0.23 to 1.86$)$ & -9.6 & $(-33.2$ to 15.0$)$ \\
\hline Trend ( $p$ value) & 0.971 & $(0.307)$ & -2.994 & $(0.244)$ & 0.946 & $(0.119)$ & -1.874 & $(0.161)$ \\
\hline \multicolumn{9}{|c|}{ Caste/ethnicity (base=Newar) } \\
\hline \multicolumn{9}{|c|}{ Dalits } \\
\hline 1990-1991 & 2.19 & (1.54 to 3.41$)$ & 85.9 & (51.3 to 120.5 ) & 2.29 & (1.29 to 5.6$)$ & 37.3 & (13.5 to 61.7$)$ \\
\hline 1998-1999 & 1.67 & (0.98 to 3.31$)$ & 42.7 & $(-1.6$ to 81.2$)$ & 1.74 & (0.76 to 7.77 ) & 22.3 & $(-12.6$ to 53.3$)$ \\
\hline 2004-2005 & 1.30 & (0.51 to 10.45$)$ & 24.6 & (-83.5 to 107.6$)$ & 3.92 & (0.48 to 56.21 ) & 39.1 & ( -25.2 to 78$)$ \\
\hline Trend ( $p$ value) & 0.922 & $(0.066)$ & -9.384 & $(0.008)$ & 1.102 & $(0.122)$ & 0.467 & $(0.807)$ \\
\hline \multicolumn{9}{|l|}{ Terai/Madhesi } \\
\hline 1990-1991 & 2.33 & (1.59 to 3.62 ) & 95.8 & (56.9 to 132.8 ) & 3.04 & (1.66 to 7.57 ) & 59.1 & (30.6 to 86.6 ) \\
\hline 1998-1999 & 1.42 & (0.87 to 2.81 ) & 26.8 & $(-12.8$ to 62.9$)$ & 1.42 & (0.63 to 6.27 ) & 12.6 & $(-22.3$ to 40.8$)$ \\
\hline 2004-2005 & 1.21 & (0.46 to 10.32 ) & 17.3 & (-93.9 to 107.9$)$ & 4.42 & (0.67 to 68.34 ) & 45.8 & (-16.4 to 91.6$)$ \\
\hline Trend ( $p$ value) & 0.930 & $(0.096)$ & -8.993 & $(0.028)$ & 1.095 & $(0.373)$ & -0.496 & $(0.888)$ \\
\hline \multicolumn{9}{|l|}{ Brahman/Chhetri } \\
\hline 1990-1991 & 1.54 & (1.09 to 2.37 ) & 39.0 & (8.6 to 66.6 ) & 1.87 & (1.05 to 4.50$)$ & 25.3 & (2.3 to 44.8 ) \\
\hline 1998-1999 & 1.21 & (0.73 to 2.35 ) & 13.1 & (-27.4 to 45.8$)$ & 1.08 & (0.47 to 4.62$)$ & 2.3 & $(-31.2$ to 26.4$)$ \\
\hline $2004-2005$ & 0.64 & (0.25 to 5.25 ) & -29.7 & $(-134.1$ to 51.9$)$ & 1.89 & ( 0.25 to 25.29 ) & 12.0 & ( -46.7 to 40.4$)$ \\
\hline Trend ( $p$ value) & 0.921 & $(0.128)$ & -6.866 & $(0.058)$ & 1.080 & $(0.298)$ & 0.172 & $(0.924)$ \\
\hline \multicolumn{9}{|l|}{ Janajati } \\
\hline 1990-1991 & 1.63 & (1.13 to 2.53 ) & 45.2 & (12.4 to 74.4 ) & 1.75 & (0.97 to 4.29 ) & 21.7 & $(-1.4$ to 42.1$)$ \\
\hline 1998-1999 & 1.30 & (0.80 to 2.63 ) & 19.1 & $(-19.3$ to 54.5$)$ & 1.37 & (0.61 to 5.65 ) & 11.0 & ( -22.3 to 37.9$)$ \\
\hline $2004-2005$ & 0.60 & (0.22 to 5.28 ) & -32.7 & (-137.1 to 49.3 ) & 1.33 & (0.15 to 21.83 ) & 4.4 & ( -54.7 to 27.6$)$ \\
\hline Trend ( $p$ value) & 0.899 & $(0.108)$ & -9.155 & $(0.056)$ & 1.029 & $(0.692)$ & -1.091 & $(0.559)$ \\
\hline \multicolumn{9}{|l|}{ Muslim } \\
\hline 1990-1991 & 2.06 & (1.36 to 3.29 ) & 76.0 & (31.9 to 119.0 ) & 2.34 & (1.17 to 5.84 ) & 38.8 & (7.7 to 67.9 ) \\
\hline 1998-1999 & 1.44 & (0.79 to 2.89 ) & 28.2 & (-18.4 to 70.5$)$ & 1.61 & (0.59 to 7.16$)$ & 18.4 & (-19.7 to 52.5$)$ \\
\hline 2004-2005 & 1.84 & (0.58 to 16.47 ) & 69.7 & (-64.5 to 204.0 ) & 6.25 & (0.62 to 83.63 ) & 70.4 & $(-16.0$ to 148.0$)$ \\
\hline Trend ( $p$ value) & 0.955 & $(0.300)$ & -4.317 & $(0.301)$ & 1.104 & $(0.187)$ & 2.133 & $(0.524)$ \\
\hline
\end{tabular}

See the web appendix file for full results. The small number of observations and possible non-linear relationships implies that the trend estimates should be treated with caution. $\mathrm{Cl}$, confidence interval; NDR, neonatal death rate; RR, rate ratio; RD, rate difference; U5DR, under-5-year-olds' death rate.

Figure 2 Under-5-year-olds and NDR (per 1000 live births) by ecological region stratified by rural-urban location for selected 2-year periods, with 95\% confidence intervals. See the web appendix file for full results. Estimates of the urban mountain region are not possible due to insufficient observations. NDR, neonatal death rate; U5DR, under-5-year-olds' death rate. This figure is only reproduced in colour in the online version.

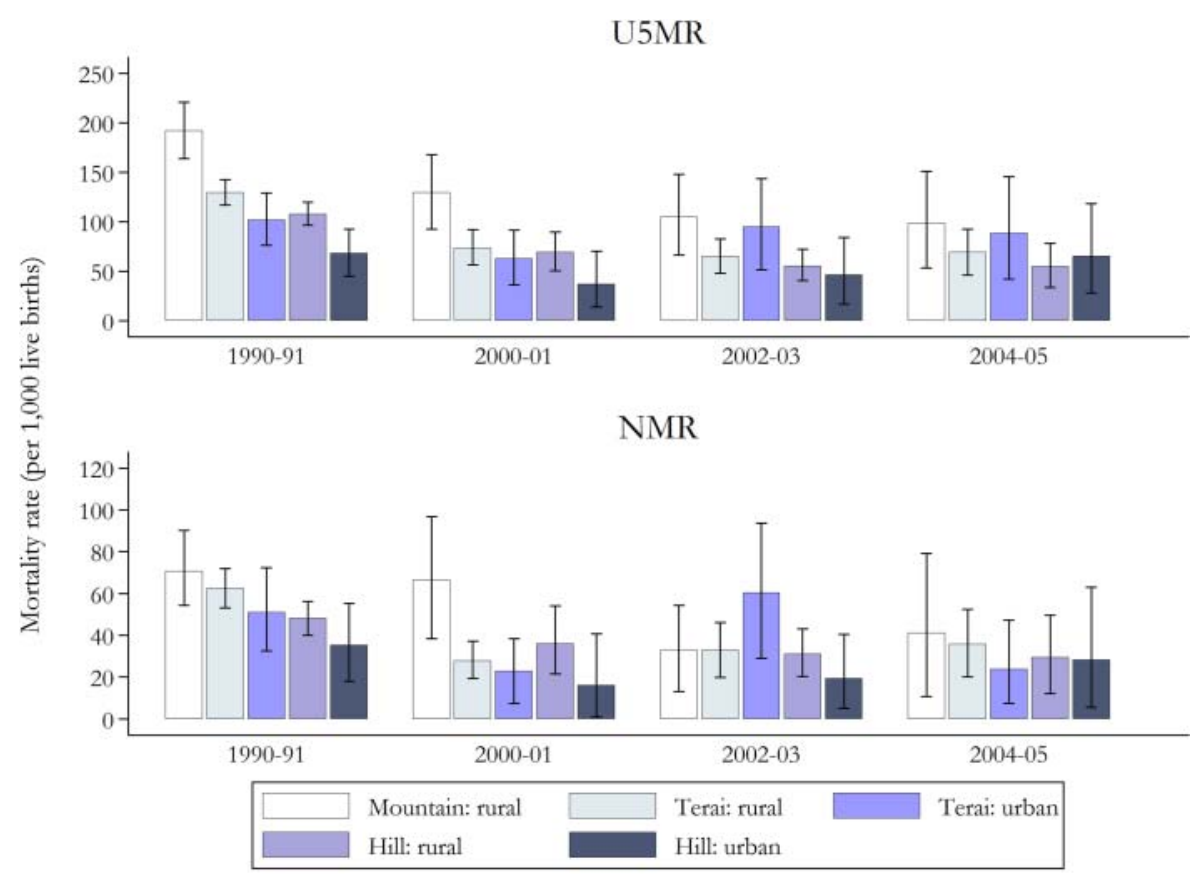

Year 
Figure 3 Under-5-year-olds' and NDR (per 1000 live births) by development regions for selected 2-year periods, with $95 \%$ confidence intervals. See the web appendix file for full results. NDR, neonatal death rate; U5DR, under-5-year-olds' death rate. This figure is only reproduced in colour in the online version.

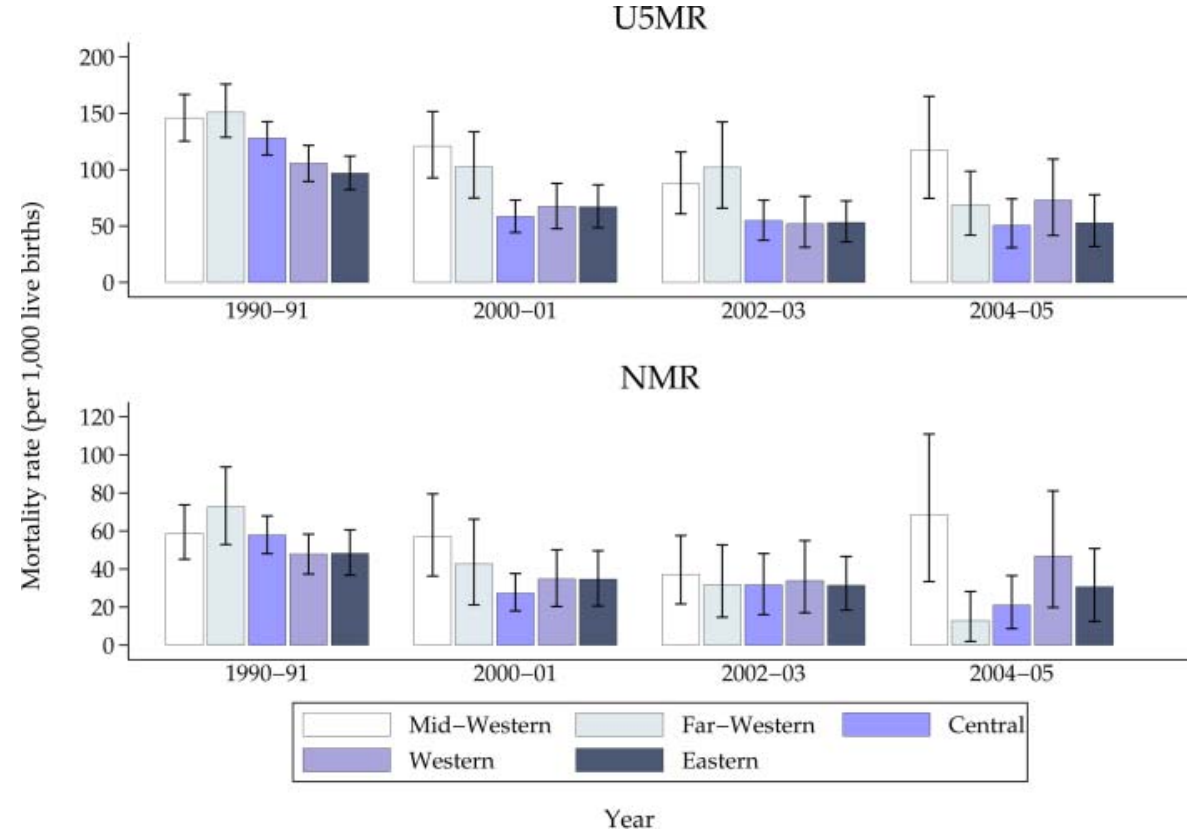

consistency in trends suggests that, even if the precise measurement of inequality is uncertain, the pattern of inequality is likely to be valid. Nonetheless, it should also be noted that the statistical power of significance tests for a linear trend are insufficient to detect small changes given the limited number of data points. Second, in addition to well-known measurement errors in survey data, our methodology does not directly deal with the potential influence of recall bias. Pooling data from multiple surveys, however, helps mitigate the recall bias to some extent where surveys overlap. Finally, possible changes achieved in the projected time period via increased efforts to reduce child mortality are not included in our forecasts, which are based on recent time trends only.

\section{CONCLUSION}

Nepal has achieved a consistent reduction in under-5-year-olds' mortality since 1990, with some gains in equity, at least in absolute terms. However, a number of communities have been left

Table 2 Inequalities in under-5-year-olds and neonatal mortality (per 1000 live births) by wealth quintiles for all years, with $95 \%$ confidence interval and $p$ values for trend

\begin{tabular}{|c|c|c|c|c|c|c|c|c|c|c|}
\hline \multirow[b]{2}{*}{ Wealth } & \multicolumn{6}{|c|}{ Relative inequalities } & \multicolumn{4}{|c|}{ Absolute inequalities } \\
\hline & RR & $95 \% \mathrm{Cl}$ & RII & $95 \% \mathrm{Cl}$ & $\mathrm{Cl}$ & $95 \% \mathrm{Cl}$ & RD & $95 \% \mathrm{Cl}$ & SII & $95 \% \mathrm{Cl}$ \\
\hline \multicolumn{11}{|l|}{ U5DR } \\
\hline 1990-1991 & 2.19 & (1.75 to 2.82 ) & 2.37 & (1.06 to 3.67 ) & -0.162 & $(-0.197$ to -0.127$)$ & 86.1 & (61.4 to 110.5 ) & 97.14 & (43.52 to 150.76 ) \\
\hline 1992-1993 & 1.94 & (1.52 to 2.53 ) & 2.25 & (0.89 to 3.60$)$ & -0.159 & $(-0.195$ to -0.124$)$ & 61.6 & (40.1 to 82.7 ) & 80.64 & (27.79 to 133.50 ) \\
\hline 1994-1995 & 1.71 & (1.32 to 2.26$)$ & 1.99 & (1.62 to 2.37 ) & -0.138 & $(-0.180$ to -0.097$)$ & 53.2 & (29.5 to 75.7 ) & 68.90 & (51.65 to 86.15 ) \\
\hline 1996-1997 & 2.42 & (1.69 to 3.64 ) & 2.21 & $(-0.30$ to 4.73$)$ & -0.160 & $(-0.212$ to -0.109$)$ & 68.6 & (42.3 to 92.8$)$ & 77.52 & ( -20.31 to 175.36$)$ \\
\hline 1998-1999 & 2.01 & (1.41 to 3.02 ) & 1.91 & (0.09 to 3.73 ) & -0.117 & $(-0.170$ to -0.064$)$ & 51.4 & (25.8 to 77.0 ) & 52.41 & $(-18.15$ to 122.98$)$ \\
\hline $2000-2001$ & 3.56 & (2.23 to 6.22 ) & 4.31 & (2.40 to 6.21 ) & -0.170 & $(-0.240$ to -0.101$)$ & 76.8 & (52.7 to 101.3 ) & 91.10 & (72.46 to 109.75 ) \\
\hline $2002-2003$ & 2.39 & (1.39 to 4.83$)$ & 2.37 & (1.14 to 3.61$)$ & -0.230 & $(-0.322$ to -0.137$)$ & 48.0 & (21.3 to 75.1 ) & 52.51 & ( 25.21 to 79.80 ) \\
\hline $2004-2005$ & 0.75 & (0.39 to 1.82$)$ & 0.76 & $(-0.06$ to 1.57$)$ & -0.083 & $(-0.203$ to 0.036$)$ & -17.9 & (-68.0 to 27.8 ) & -18.86 & (-90.34 to 52.62 ) \\
\hline Trend ( $p$ value) & 0.948 & $(0.484)$ & 0.936 & $(0.413)$ & 0.002 & $(0.814)$ & -8.845 & $(0.062)$ & -10.848 & $(0.042)$ \\
\hline \multicolumn{11}{|l|}{ NDR } \\
\hline 1990-1991 & 1.81 & (1.32 to 2.65$)$ & 1.77 & (0.58 to 2.97 ) & -0.066 & $(-0.109$ to -0.023$)$ & 30.4 & (14.1 to 47.5 ) & 30.69 & $(-2.96$ to 64.34$)$ \\
\hline 1992-1993 & 1.37 & (0.92 to 2.06$)$ & 1.44 & (0.20 to 2.68 ) & -0.077 & $(-0.124$ to -0.031$)$ & 11.2 & (-2.9 to 24.7$)$ & 15.34 & ( -20.31 to 50.99 ) \\
\hline 1994-1995 & 1.24 & (0.84 to 1.96$)$ & 1.23 & (1.00 to 1.47$)$ & -0.074 & $(-0.125$ to -0.024$)$ & 9.5 & (-8.2 to 26.4$)$ & 9.52 & (0.82 to 18.22 ) \\
\hline 1996-1997 & 2.34 & (1.36 to 4.55$)$ & 2.45 & (1.30 to 3.6$)$ & -0.042 & $(-0.104$ to 0.019$)$ & 33.5 & (13.4 to 52.5 ) & 36.94 & (20.40 to 53.49 ) \\
\hline 1998-1999 & 1.73 & (0.98 to 3.31 ) & 1.49 & ( -0.76 to 3.73$)$ & -0.062 & $(-0.130$ to 0.007$)$ & 20.1 & ( -0.6 to 40.1 ) & 15.67 & (-42.02 to 73.36$)$ \\
\hline $2000-2001$ & 4.30 & (2.06 to 12.06$)$ & 4.25 & $(-1.08$ to 9.59$)$ & -0.107 & $(-0.184$ to -0.031$)$ & 36.1 & (19.5 to 51.6 ) & 43.18 & (17.71 to 68.64 ) \\
\hline $2002-2003$ & 2.23 & (1.11 to 7.09 ) & 1.89 & (0.19 to 3.59 ) & -0.153 & $(-0.244$ to -0.061$)$ & 22.3 & (3.6 to 42.0 ) & 20.22 & (-6.23 to 46.66$)$ \\
\hline $2004-2005$ & 0.39 & (0.12 to 1.86$)$ & 0.58 & $(-1.21$ to 2.37$)$ & -0.088 & $(-0.192$ to 0.015$)$ & -23.6 & (-59.7 to 7.8$)$ & -17.38 & $(-110.03$ to 75.26$)$ \\
\hline Trend ( $p$ value) & 0.944 & $(0.625)$ & 0.962 & $(0.695)$ & -0.008 & $(0.147)$ & -3.055 & $(0.341)$ & -2.767 & $(0.381)$ \\
\hline
\end{tabular}

The small number of observations and possible non-linear relationships implies that the trend estimates should be treated with caution. Additionally, since the bounds of the $\mathrm{Cl}$ depend on the mean of mortality, comparisons over time must be treated cautiously.

$\mathrm{Cl}$, concentration index; NDR, neonatal death rate; RD, rate difference; RII, relative index of inequality; RR, rate ratio; SII, slope index of inequality; U5DR, under-5-year-olds' death rate. 
behind. The urban poor and the urban populations of the terai are particularly at risk, and require attention to overcome financial and social barriers to care. Similarly, strategies that address the social exclusion and poverty of rural populations are likely to be essential to overcoming geographical isolation. Importantly, to achieve further reductions in under-5-year-olds' mortality, the policy emphasis will need to shift to address newborns' survival. Among other things, this would mean a strong focus on improving the care provided to all mothers and to all newborns in the first $48 \mathrm{~h}$ of life, independent of ethnicity, wealth or residential location.

\section{What is already known on this subject}

- Very little is known about patterns in child mortality at subnational level in many developing countries. Despite steady improvement in maternal and child health indicators it is still uncertain whether the improved performance in Nepal was equitable. Anecdotal evidence suggests that inequality in access and utilisation of health services, and ultimately health outcomes, exist at the subnational level.

\section{What this study adds}

- The quantitative analysis shows that disparities in under-5-year-olds' mortality by most equity markers have decreased in absolute terms but have remained stable in relative terms. A similar pattern is observed with respect to neonatal inequalities, although no significant trend is found, suggesting that such inequalities remain.

- In a number of cases, the reduction in absolute inequalities is due to stagnating mortality in urban areas.

- Possible upward trends in inequalities across development regions were found, at least in relative terms.

Acknowledgements We appreciate the timely support and assistance of people within the Nepalese Government, New ERA, UNICEF Nepal and the Nossal and Burnet Institutes. Special thanks to Dr Prakash Dev Pant and Dr Yogendra Prasai for their consistent support and valuable insights and guidance. The study would not have been possible without the hard work and dedication of the project staff at the School of Population Health, the University of Queensland. We thank the editor and three anonymous reviewers for their comments and suggestions.

Contributors KHM and EJS designed the study. KHN wrote the first draft of the manuscript. AH undertook the statistical analysis with contributions from $\mathrm{KHN}$ and EJS. AM, CM and AH contributed to the interpretation of the results. All the authors contributed to subsequent drafts, and approved the submitted manuscript.

Funding The research described in this paper is made possible through the Bill and Melinda Gates Foundation, grant ID 52125, URL: www.gatesfoundation.org; and the Australian Agency for International Development (AusAID), grant ID 47734, URL: www.ausaid.gov.au. The funders had no role in study design, data collection and analysis, decision to publish, or preparation of the manuscript.

\section{Competing interests None.}

Provenance and peer review Not commissioned; externally peer reviewed.

\section{REFERENCES}

1 Ministry of Health and Population [Nepal], New ERA, Macro International Inc. Nepal Demographic and Health Survey 2006. Kathmandu, Nepal and Calverton,
Maryland, USA: Ministry of Health and Population, New ERA, and Macro International Inc., 2007.

2 Malla DS, Giri K, Karki C, et al. Achieving Millennium Development Goals 4 and 5 in Nepal. BJOG 2011;118:60-8.

3 Pradhan YV, Upreti SR, KC NP, et al. Newborn survival in Nepal: a decade of change and future implications. Health Policy Plan 2012;27:iii57-71.

4 Government of Nepal, New ERA, ICF International. Nepal Demographic and Health Survey 2011. Kathmandu, 2012.

5 United Nations Development Programme, Government of Indonesia. Country Programme Action Plan, Indonesia. Jarkatar, 2006.

6 World Bank. Nepal: operational issues and prioritization of resources in the health sector. New York: The World Bank, 2000.

7 Bennett L. Gender, caste and ethnic exclusion in Nepal: following the policy process from analysis to action. Presented at the Arusha Conference "New Frontiers of Social Policy: Development in a Globalizing World", 12-15 December 2005.

8 Bennett J, Hoogendoorm A, de Pee S, et al. Assistance to recovery and nutritional rehabilitation. Full report of the Mid-term Evaluation of the Indonesia PRRO 10069, Office of Evaluation: World Food Programme, 2006.

9 Chhetry D. Understanding rural poverty in Nepal. Paper delivered at the Asia and Pacific Forum on Poverty: Reforming Policies and Institutions for Poverty Reduction, 5-9 February 2001.

10 Hotchkiss DR. Expansion of rural health care and the use of maternal services in Nepal. Health Place 2001;7:39-45.

11 Nguyen $\mathrm{KH}$, Morgan A, Morgan C, et al. Developing an investment case for financing equitable progress towards MDGs 4 and 5 in the Asia Pacific Region: Equity Report for Nepal. Brisbane, Australia: School of Population Health, The University of Queensland, 2011.

12 Ministry of Health [Nepal], New ERA, ORC Macro. Nepal Demographic and Health Survey 2001. Calverton, Maryland, USA: Family Health Division, Ministry of Health; New ERA, and ORC Macro, Family Health Division, Ministry of Health; New ERA; and ORC Macro, 2002

13 Adhikari R, Podhisita C. Household headship and child death: evidence from Nepal. BMC Int Health Hum Rights 2010;10:13.

14 Dhakal S. Maternal mortality falls in Nepal but inequalities exist. The Lancet 2007:370:1301

15 Bennett L, Dahal DR, Govindasamy P. Caste, ethnic, and regional identity in Nepal: further analysis of the 2006 Nepal Demographic and Health Survey. Maryland, USA: Macro International Inc, 2008

16 Bennett L, Tamang S, Onta P, et al. Unequal citizens: gender, caste and ethnic exclusion in Nepal. Kathmandu, Nepal: The World Bank and Department for International Development, 2006.

17 Gellner DN. Caste, ethnicity and inequality in Nepal. Economic and Political Weekly 19 May 2007:1823-8.

18 Nielsen L. Equity in Health and Health Care in Nepal: Experiences from Nepal Health Sector Reform. Commentary (unpublised), 2004.

19 Tanka Prasad Acharya Memorial Foundation. Analysis of caste, ethnicity and gender data from 2001 population census in Preparation for Poverty Mapping and Wilder PRSP Monitoring. A report submitted to DFID, Kathmandu, Nepal, mimeo (unpublished), 2005.

20 Bartley M. Health inequality: an introduction to theories, concepts and methods. Cambridge, UK: Polity Press, 2004.

21 Barros AJD, Ronsmans C, Axelson $\mathrm{H}$, et al. Equity in maternal, newborn, and child health interventions in Countdown to 2015: a retrospective review of survey data from 54 countries. The Lancet 2012;379:1225-33.

22 Victora CG, Wagstaff A, Schellenberg JA, et al. Child survival IV Applying an equity lens to child health and mortality: more of the same is not enough. The Lancet 2003:362:233-41

23 Wagstaff $A$, Paci $P$, van Doorslaer $E$. On the measurement of inequalities in health. Soc Sci Med 1991:33:545-57.

24 Central Bureau of Statistics Nepal. Nepal Living Standards Survey 1995. Kathmandu, Nepal: Central Bureau of Statistics, 1996

25 Central Bureau of Statistics Nepal. Nepal Living Standards Survey 2003/04: Statistical Report Vol 1. Kathmandu, Nepal: Central Bureau of Statistics, 2004.

26 Ministry of Health and Population [Nepal], New ERA, Macro International Inc. Nepal Demographic and Health Survey 1996. Kathmandu, Nepal: Ministry of Health and Population, New ERA, and Macro International Inc., 1997.

27 Rajaratnam JK, Tran LN, Lopez AD, et al. Measuring under-five mortality: validation of new low-cost methods. PLoS Medicine 2010;7:e1000253.

28 Cleveland W, Loader C. Smoothing by local regression: principles and methods. In: Haerdle W, Schimek M, eds. Statistical theory and computational aspects of smoothing. New York, USA: Springer, 1996;10-49.

29 Murray CJL, Laakso T, Shibuya K, et al. Can we achieve Millennium Development Goal 4 ? New analysis of country trends and forecasts of under-5 mortality to 2015 . The Lancet 2007;370:1040-54.

30 Filmer D, Pritchett LH. Estimating wealth effect without expenditure data —or tears: an application to educational enrollments in states of India. Demography 2001;38:115-32.

31 Mackenbach J, Kunst A. Measuring the magnitude of socio-economic inequalities in health: an overview of available measures illustrated with two examples from Europe. Soc Sci Med 1997:44:757-71. 
32 Mackenbach J, Stirbu I, Roskam A-J, et al. Socioeconomic inequalities in health in 22 European countries. N Engl J Med 2008;358:2468-81.

33 Blakely T, Tobias M, Atkinson J. Inequalities in mortality during and after restructuring of the New Zealand economy: repeated cohort studies. BMJ 2008:336:371-5.

34 Pamuk E. Social class inequality in mortality from 1921 to 1972 in England and Wales. Popul Stud 1985;39:17-31.

35 Hayes LJ, Berry G. Sampling variability of the Kunst-Mackenbach relative index of inequality. J Epidemiol Community Health 2002;56:762-5.

36 Erreygers $\mathrm{G}$, Van Ourti T. Measuring socioeconomic inequality in health, health care and health financing by means of rank-dependent indices: a recipe for good practice. J Health Econ 2011;30:685-94.

37 Wagstaff $A$. The bounds of the concentration index when the variable of interest is binary, with an application to immunization inequality. Health Econ 2005;14:429-32.

38 Bhutta ZA, Chopra M, Axelson H, et al. Countdown to 2015 decade report (2000-10): taking stock of maternal, newborn, and child survival. The Lancet 2010;375:2032-44.

39 Rajaratnam JK, Marcus JR, Flaxman AD, et al. Neonatal, postneonatal, childhood, and under-5 mortality for 187 countries, 1970-2010: a systematic analysis of progress towards Millennium Development Goal 4. The Lancet 2010;375:1988-2008.
40 Ghimire M, Pradhan YV, Maskey MK. Community-based interventions for diarrhoeal diseases and acute respiratory infections in Nepal. Bull World Health Organ 2010;88:216-21.

41 United Nations Human Settlements Programme. Slums of the World: the face of urban poverty in the new millennium. Nairobi, Kenya: United Nations Human Settlements Programme (UN-HABITAT), 2003.

42 Asian Development Bank. Environment assessment of Nepal: emerging issues and challenges. Kathmandu, Nepal: Asian Development Bank and International Centre for Integrated Mountain Development, 2008.

43 Bhattarai K, Conway D. Urban vulnerabilities in the Kathmandu Valley, Nepal: visualizations of human/hazard interactions. J. Geogr Inf Syst 2010;2:63-84.

44 Sclar ED, Garau P, Carolini G. The 21st century health challenge of slums and cities. The Lancet 2005;365:901-3.

45 Moreno EL, Warah R. The state of the world's cities report 2006/07: urban and slum trends in the 21st century. UN Chronicle 2006;43:24.

46 USAID, Extending Service Delivery Project. Nepal: Reaching the Urban Poor with Family Planning/HTSP messages. Washington D.C., USA, 2007.

47 Ministry of Health and Population (MOHP) [Nepal]. Nepal Health Sector Programme Implementation Phase 2: 2010-2015. Kathmandu, Nepal: Ministry of Health and Population, 2010 